\title{
A COMPARISON OF BIOACTIVE CONSTITUENTS AND IN VITRO ANTIOXIDANT POTENTIAL OF ASTHMA WEED (EUPHORBIA HIRTA), WITH THOSE OF OTHER ANTI- ASTHMATIC PLANTS GROWING IN TABUK REGION, SAUDI ARABIA
}

\author{
Al-Mutairi, K. A. - MoBin, M. - KHAN, M. N. ${ }^{*}$ \\ Department of Biology, Faculty of Science, University of Tabuk, Tabuk 71491, Saudi Arabia \\ *Corresponding author \\ e-mail:nasirmn4@gmail.com
}

(Received 24 $4^{\text {th }}$ May 2019; accepted $25^{\text {th }}$ Oct 2019)

\begin{abstract}
Euphorbia hirta (asthma weed) has been documented as an effective herb for the treatment of asthma and associated symptoms. This study was aimed at comparing the bioactive constituents and in vitro antiradical activity of asthma weed with other commonly growing anti-asthmatic plants such as Pergularia tomentosa, Dipterygium glaucum and Acalypha indica in Tabuk region of Saudi Arabia. The results showed that the total phenol and flavonoid content of methanolic leaf extract of E. hirta was highest compared to the other anti-asthmatic plants. E. hirta was also recorded to have the maximum total antioxidant capacity, 1, 1-diphenyl-2-picryl-hydrazyl (DPPH) antiradical activity and nitric oxide (NOX) scavenging activity. However, hydrogen peroxide scavenging activities and metal chelating activities were as the highest for the methanolic extracts of $D$. glaucum and $P$. tomentosa, respectively compared to the other anti-asthmatic plants. It may be concluded that the abundance of phenol and flavonoids along with maximum antioxidant capacity, DPPH antiradical activity and NOX scavenging activity of E. hirta makes it worthy of using as an effective anti-asthmatic plant.
\end{abstract}

Keywords: flavonoids, oxidative stress, antioxidant capacity, antiradical scavenging activity, phenols

\section{Introduction}

Asthma is a chronic lung disease, inducing narrowing of airways and changes in the levels of eosinophils, mast cells, lymphocytes, cytokines and other inflammatory cell products (Rivera et al., 2011). Asthma is a common chronic disease that is estimated to affect as many as 339 million people worldwide (WHO, 2018). However, Bousquet et al. (2005) predicted that 100 million more will be affected by asthma by 2025 . It causes a high global burden of death and disability, with around 1000 people dying each day from asthma, and is in the top 20 causes of years of life lived with disability (WHO, 2018). Nearly 2 million people are affected by asthma in the Kingdom of Saudi Arabia. There are no complete cures of asthma and currently available modern therapies have been associated with many side effects. So, to find an effective low risk, a non-drug strategy that may furnish a valuable adjunctive or alternative therapy in asthma management is both alluring and timely.

Of late, medicinal plants have attracted a huge interest due to the inherent antioxidant potential of the phytochemicals that reduce the free-radical induced oxidative damage. It is estimated that $80 \%$ of the world population rely on drugs obtained from plants, for their primary health care needs (WHO, 2019). It has been established that climate change may affect the chemical composition and, ultimately the survival of some medicinal plants. Climate change has a remarkable effect on secondary metabolites and other compounds that plants produce, which are usually the basis for their medicinal 
activity (Khan et al., 2016; Yang et al., 2018). Phytochemical screening by several workers has unveiled the presence of various bioactive constituents such as phenols, flavonoids, alkaloids, terpenoids and saponins (Altemimi et al., 2017; Verma et al., 2018; Sai et al., 2019; Batool et al., 2019). Medicinal plants that may be employed for the treatment of asthma should have anti-allergic, anti-inflammatory, antihistaminic and immunomodulatory properties. It has been observed that the supplements with antioxidant properties are potentially effective in decreasing the degree of bronchoconstriction as they suppress the pro-inflammatory episodes by counteracting reactive oxygen species and reactive nitrogen species (Kurutas, 2016; Bagatini et al., 2018).

Tabuk, the northern province of Saudi Arabia (Fig. 1) is a region largely characterized by asymmetrical topography ranging from plains to low and high mountains that create a highly distinct environmental variable of extreme cold to extreme hot (Khan et al., 2016). Diversified topography coupled with varied environmental conditions supports the growth of several medicinally important plants in this region. Of these, Euphorbia hirta (Euphorbiaceae), Pergularia tomentosa (Asclepiadaceae), Dipterygium glaucum (Capparidaceae) and Acalypha indica (Euphorbiaceae) have long been used in traditional medicine to treat asthma (Kumar et al., 2010; Youssouf et al., 2007; Zahidin et al., 2017; Alamgeer et al., 2018; Rayyan et al., 2018). Euphorbia hirta is known as asthma weed, spurge or milkweed and used to treat respiratory complications. Although, various studies have been performed on the phytochemical constituents of these plants, but meagre research was carried out on the comparative study of antioxidant potential of these plants. Therefore, the objective of the current study was to compare the antioxidant potential and secondary metabolites of asthma weed with other anti-asthmatic plants found in Tabuk region.

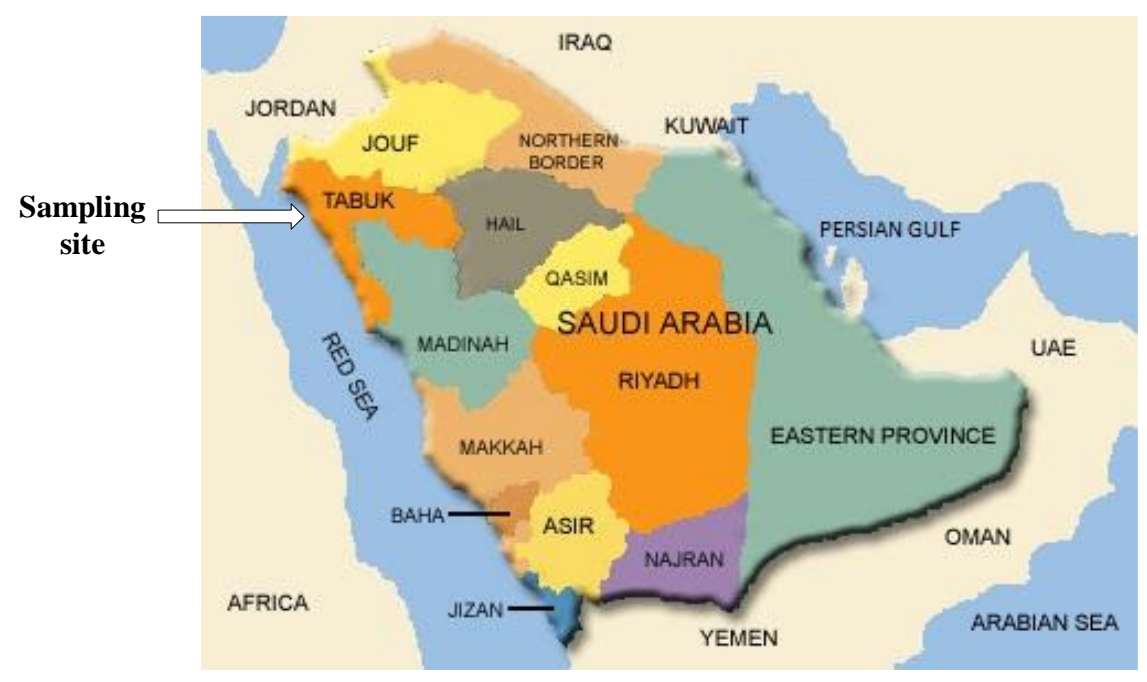

Figure 1. Map showing sampling site (Tabuk, Saudi Arabia). (Source: Google images)

\section{Materials and methods}

\section{Plant collection}

The plants were collected from Tabuk, the Northern Province of Saudi Arabia (latitude $28^{\circ} 22^{\prime} 59^{\prime \prime} \mathrm{N} ; 36^{\circ} 34^{\prime} 59^{\prime \prime} \mathrm{E}$, altitude $773 \mathrm{~m}$ ). The region is characterized by its 
hyper-arid climate, high evaporation rate and low precipitations during December to February. The region is bounded by Red sea on the west to the Hufa depressions in the east. Four plant species (E. hirta, P. tomentosa, D. glaucum and A. indica) were collected at flowering stage. At collection site five $10 \mathrm{~m} \times 10 \mathrm{~m}$ plots, at the distance of $20 \mathrm{~m}$ each, were established randomly during the study. Four plants of each species from each plot were collected randomly. Finally, five healthy plants of each species were selected and were used for assessing various characteristics. The plant materials were authenticated by Dr. M. Nasir Khan. Collected plants were dried in shade under dark. Air-dried leaf samples were ground to a fine powder (80 mesh) using an electric blender and stored in a clean labeled air-tight container as replicates for assessing various characteristics.

\section{Plant extracts}

Powdered leaf sample (100 g) of each plant was extracted with methanol for $24 \mathrm{~h}$ using Soxhlet apparatus (Borosil, BRL_3840020). The extracts were separated from the solids by filtration with Whatman No. 1 filter paper. The remaining solids were extracted twice with the same methanol and extracts combined. The extracts were concentrated under reduced pressure at $45^{\circ} \mathrm{C}$ in a rotary evaporator (EYELA, Tokyo, Japan) and kept in a refrigerator at $4{ }^{\circ} \mathrm{C}$ until analyzed.

\section{Estimation of total phenol}

The content of total phenols was estimated by the Folin-Ciocalteu method with little modification of Cevallos-Casals and Cisneros-Zevallos et al. (2005). From each sample, $0.5 \mathrm{ml}$ of methanolic extract was added to $2.5 \mathrm{ml}$ of Folin-Ciocalteu reagent and $2 \mathrm{ml}$ of sodium carbonate $1 \mathrm{M}$. The tubes were incubated at $45^{\circ} \mathrm{C}$ for $30 \mathrm{~min}$. The absorbance of total phenolics was measured at $765 \mathrm{~nm}$ using Hewlett Packard, $\mathrm{UV} /$ visible light. Total phenolics content was expressed as mg gallic acid equival ents per g dry weight.

\section{Estimation of total flavonoids}

Total flavonoid content in the methanolic extracts was measured spectrophotometrically (CE 2021, Cecil, Cambridge, England), following the method of Marinova et al. (2005). $4 \mathrm{ml}$ of water was added to $1 \mathrm{ml}(500 \mathrm{mg} / \mathrm{ml})$ extract or standard catechin solution and $0.3 \mathrm{ml}$ of $5 \% \mathrm{NaNO}_{2}$. After keeping it for $5 \mathrm{~min}, 0.3 \mathrm{ml} 10 \%$ $\mathrm{AlCl}_{3}$ was added. To this mixture, after $6 \mathrm{~min} 2 \mathrm{ml} 1 \mathrm{M} \mathrm{NaOH}$ was added and the total volume was made up to $10 \mathrm{ml}$ with water. The solution was thoroughly mixed, and the absorbance was recorded against a prepared reagent blank at $510 \mathrm{~nm}$. Total flavonoid content of was expressed as catechin equivalents in mg per g dry weight.

\section{Assay of total antioxidant capacity}

Total antioxidant capacity was determined by the method described by Prieto et al. (1999). $0.1 \mathrm{ml}$ of methanolic plant extract was added to $1 \mathrm{ml}$ of reagent solution $(0.6 \mathrm{~mol} / \mathrm{l}$ sulfuric acid, $28 \mathrm{mmol} / \mathrm{l}$ sodium phosphate and $4 \mathrm{mmol} / \mathrm{l}$ ammonium molybdate). The tubes were heated at $95{ }^{\circ} \mathrm{C}$ for $90 \mathrm{~min}$. The absorbance of each solution was recorded at $695 \mathrm{~nm}$ against a blank. The antioxidant capacity was expressed as mg gallic acid equivalent per gram dry weight (mg GAE/g DW). 


\section{Anti-radical capacity}

\section{Determination of 1, 1-diphenyl-2-picryl-hydrazyl (DPPH) free radical scavenging}

The free radical scavenging capacity of methanolic extracts of different plants was recorded using DPPH method as described by Thaipong et al. (2006). $5 \mathrm{ml}$ of $0.004 \%$ freshly prepared methanolic solution of DPPH (2, 2-diphenyl-1-picrylhydrazyl) were added to $50 \mu \mathrm{l}$ of different concentrations of sample. After $30 \mathrm{~min}$ in the dark at room temperature, the absorbance was recorded spectrophotometrically against a blank at $517 \mathrm{~nm}$. DPPH free radical scavenging activity was expressed as the percentage inhibition.

\section{Nitric oxide (NOX) scavenging activity}

To estimate NOX radical inhibition activity, method described by Marcocci et al. (1994) was followed with little modifications. Briefly, sodium nitropruside $(5 \mathrm{mM}$, $\mathrm{pH}$ 7.4) in phosphate buffer saline was mixed with $3 \mathrm{ml}$ of different concentrations of methanolic plant extracts and incubated at $25{ }^{\circ} \mathrm{C}$ for $150 \mathrm{~min}$. From this incubated solution, $0.5 \mathrm{ml}$ was taken and mixed with $0.5 \mathrm{ml}$ Griess reagent $[(1.0 \mathrm{ml}$ sulfanilic acid reagent $(0.33 \%$ in $20 \%$ glacial acetic acid at room temperature for 5 min with $1 \mathrm{ml}$ of naphthylethylenediamine dichloride $(0.1 \% \mathrm{w} / \mathrm{v})]$. After $30 \mathrm{~min}$ of incubation, absorbance was recorded at $540 \mathrm{~nm}$. A standard solution of ascorbic acid was treated in the same way with the Griess reagent as a positive control. NOX scavenging activity was expressed as the percentage inhibition.

\section{Hydrogen peroxide $\left(\mathrm{H}_{2} \mathrm{O}_{2}\right)$ scavenging activity}

The ability of the extracts to scavenge $\mathrm{H}_{2} \mathrm{O}_{2}$ was estimated based on the method of Ruch et al. (1989). A solution of $\mathrm{H}_{2} \mathrm{O}_{2}(40 \mathrm{mM})$ was prepared in phosphate buffer (pH 7.4). The concentration of $\mathrm{H}_{2} \mathrm{O}_{2}$ was determined by absorption at $230 \mathrm{~nm}$ using a spectrophotometer. Plant extracts in methanol were added to a $\mathrm{H}_{2} \mathrm{O}_{2}$ solution $(0.6 \mathrm{ml}$, $40 \mathrm{mM}$ ). The absorbance of $\mathrm{H}_{2} \mathrm{O}_{2}$ at $230 \mathrm{~nm}$ was noted after 10 min against a blank solution containing phosphate buffer without $\mathrm{H}_{2} \mathrm{O}_{2}$. Ascorbic acid was used as positive control. $\mathrm{H}_{2} \mathrm{O}_{2}$ scavenging activity was expressed as the percentage inhibition.

\section{Metal chelating activity}

The formation of ferrous ion-ferrozine complex was recorded to estimate the ferrous level according to Decker and Welch (1990). The reaction mixture consisted of different concentration of plant extracts and $0.1 \mathrm{ml}$ of $2 \mathrm{mM}$ ferrous chloride. $0.2 \mathrm{ml}$ of $5 \mathrm{mM}$ ferrozine was added to this mixture to initiate the reaction and left to stand at room temperature for $10 \mathrm{~min}$. The absorbance of the solution was measured at $562 \mathrm{~nm}$. Ascorbic acid was used as positive control. The chelating activity was expressed as percentage of inhibition.

\section{Statistical analyses}

The data were analyzed statistically using analysis of variance (ANOVA), data were presented as average of five determinations with LSD at $5 \% \pm$ SE. Differences between the means were compared by Duncan's multiple-range test at the level of $p<0.05$ using SPSS Ver. 11 statistical software (SPSS Inc., Chicago, IL, USA). IC 50 values were calculated by employing linear regression analysis. 


\section{Results and discussion}

Asthma is an inflammatory disease of the lungs and the present endevour is to control the inflammation. As in Table 1, methanolic leaf extracts of E. hirta, P. tomentosa, D. glaucum and A. indica showed significant amount of phenolic compounds. The total phenol content of the investigated plants differed significantly. $E$. hirta, the asthma weed has $13.9 \%, 21.1 \%$ and $7.3 \%$ more phenol than the $P$. tomentosa, $D$. glaucum and $A$. indica, respectively. We have recorded a higher amount of total phenol in these anti-asthmatic plants than that of other anti-asthmatic plants such as Matricaria recutita (Al-Dabbagh et al., 2019) but lower than the Helichrysum species (Albayrak et al., 2010).

Table 1. Total phenols, flavonoids and antioxidant capacity of methanolic extracts of leaves of anti-asthmatic plants Euphorbia hirta, Pergularia tomentosa, Dipterygium glaucum and Acalypha indica

\begin{tabular}{c|c|c|c}
\hline Anti-asthmatic plants & $\begin{array}{c}\text { Total phenols } \\
\text { (mg GAE/g DW) }\end{array}$ & $\begin{array}{c}\text { Total flavonoids } \\
\text { (mg CE/g DW) }\end{array}$ & $\begin{array}{c}\text { Antioxidant capacity } \\
\text { (mg GAE/g DW) }\end{array}$ \\
\hline Euphorbia hirta & $87.7 \pm 4.2$ & $74.3 \pm 3.1$ & $67.4 \pm 3.2$ \\
Pergularia tomentosa & $75.5 \pm 3.1$ & $51.7 \pm 2.1$ & $61.2 \pm 2.9$ \\
Dipterygium glaucum & $69.2 \pm 2.9$ & $45.7 \pm 2.0$ & $54.9 \pm 2.3$ \\
Acalypha indica & $81.3 \pm 3.7$ & $58.7 \pm 2.7$ & $63.7 \pm 3.5$ \\
\hline LSD at 5\% & 3.09 & 2.41 & 1.86 \\
\hline
\end{tabular}

Average of five determinations is presented with LSD at $5 \% \pm \mathrm{SE}$

Flavonoids, low-molecular weight polyphenolic plant secondary metabolites are known to play a role in prevention and management of asthma. Recent in vitro and in vivo studies on anti-allergic and anti-asthmatic properties of flavonoids have strongly indicated that a suitable intake of flavonoids may complement the dietary treatment and/or preventive strategy for asthma or other allergic diseases in humans (Tanaka, 2014; Tanaka et al., 2019). Perusal of the data shows a significant difference among the species in the level of flavonoids (Table 1). Higher level of flavonoids were noted in the asthma weed $E$. hirta $(74.3 \pm 3.1 \mathrm{mg} \mathrm{CE} / \mathrm{g} \mathrm{DW})$ which was $30.4 \%, 38.5 \%$ and $21 \%$ higher than $P$. tomentosa $(51.7 \pm 2.1 \mathrm{mg} \mathrm{CE} / \mathrm{g} \mathrm{DW})$, D. glaucum $(45.7 \pm 1.98 \mathrm{mg} \mathrm{CE} / \mathrm{g}$ DW) and A. indica (58.7 $\pm 2.7 \mathrm{mg}$ CE/g DW), respectively. Garcia-Larsen et al. (2018) have found a direct association between flavonoid intake and asthma prevalence and severity.

We carried out the phosphomolybdenum assay to determine the antioxidant capacity of methanolic leaf extracts of E. hirta, P. tomentosa, D. glaucum and A. indica. This method is based on the reduction of Mo (VI) to Mo (V) by the antioxidant compounds and the formation of green Mo (V) complexes with a maximal absorption at $695 \mathrm{~nm}$ (Prieto et al., 1999). Analysis of variance showed that there was a significant difference among the studies plant species for antioxidant capacity. The methanolic extract of $E$. hirta had the maximum antioxidant activity with a value of $67.4 \mathrm{mg} \mathrm{GAE} / \mathrm{g}$ DW. The minimum antioxidant capacity was recorded in the methanolic extract of D. glaucum with a value of $54.9 \mathrm{mg}$ GAE/g DW (Table 1). Anti-asthmatic plant s such as Eriobotrya japonica and Tussilago farfara showed a much higher antioxidant capacity than the plants which we studied (Song et al., 2010; Norani et al., 2019). Phytochemical 
attributes such as flavonoids, carotenoids and cinnamic acid derivatives have been ascribed to contribute to the total antioxidant capacity (Tyśkiewicz et al., 2019). As, we know that oxidative stress is strongly linked with most of the features of asthma. The phytochemical preparations that are being able to scavenge these free radicals may help to relieve the symptoms of asthma. The free radical scavenging activities of methanolic leaf extracts of E. hirta, P. tomentosa, D. glaucum and A. indica were assessed by DPPH method. DPPH, stable free radicals that accept an electron or hydrogen radical and get converted in to yellow-coloured diphenylpicylhydrazine, a diamagnetic molecule. The reduction capacity of DPPH is estimated by decrease in the absorbance at $517 \mathrm{~nm}$ induced by antioxidants. As shown in Figure 2, the DPPH radical scavenging activities of methanolic leaf extracts of different plants shown to occur in a dosedependent manner. The concentration required to inhibit 50\% radical-scavenging activity $\left(\mathrm{IC}_{50}\right)$ was established from the results of a series of concentrations evaluated. A lower $\mathrm{IC}_{50}$ value corresponds to a larger scavenging activity. The rank order of potency showed that the methanolic leaf extracts of E. hirta was 2.7-, 2.5- and 1.9 -fold more powerful than the

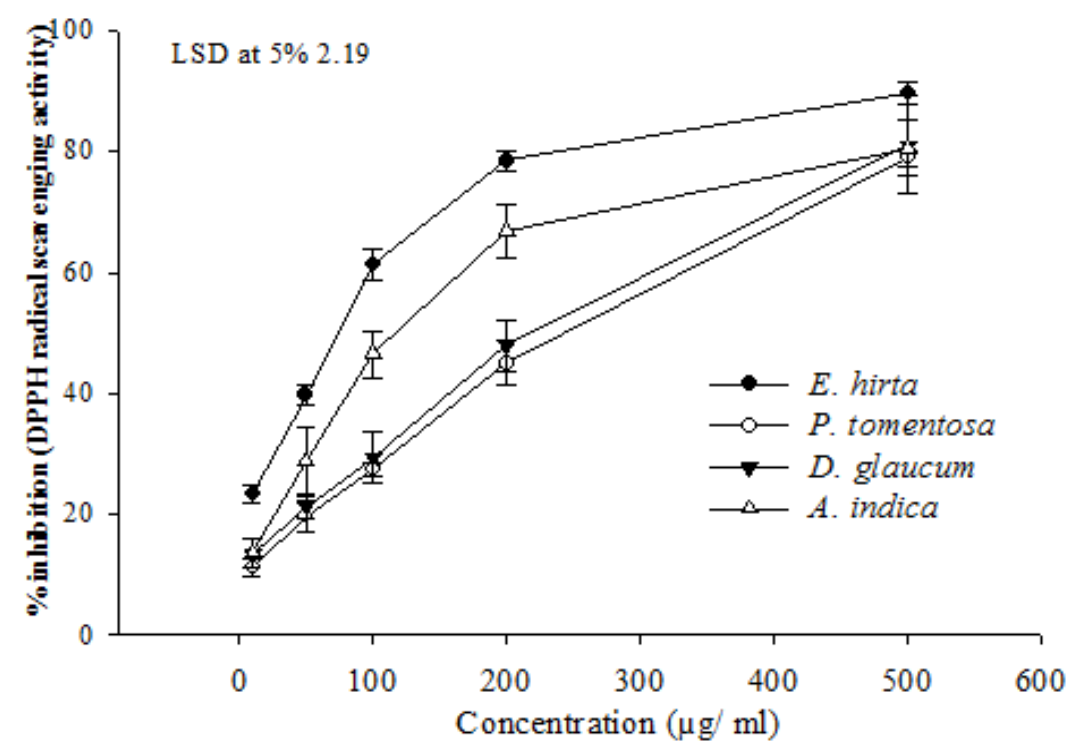

Figure 2. DPPH radical scavenging activities of the methanolic extracts of anti-asthmatic plants Euphorbia hirta, Pergularia tomentosa, Dipterygium glaucum and Acalypha indica. Average of five determinations is presented with $L S D$ at $5 \% \pm S E$

P. tomentosa, D. glaucum and A. indica, respectively. The scavenging effect of methanolic extracts on the DPPH radical expressed as $\mathrm{IC}_{50}$ values was in the following order: E. hirta $>$ A. indica $>$ D. glaucum $>$ P. tomentosa (Fig. 3). The substantial antioxidant activity of $E$. hirta could be due to the presence of sesquiterpene lactones and quercetin in flavonoids in the methanolic extracts (Williams et al., 2004; Gupta et al., 2017).

$\mathrm{H}_{2} \mathrm{O}_{2}$ is very lethal as being able to cross the biological membrane and serve as a precursor for potentially toxic hydroxyl radical (Das and Roychoudhury, 2014). The hydroxyl radical is an extremely reactive free radical capable of damaging almost every molecule found in living cells (Das and Roychoudhury, 2014). As in Figure 3, the methanolic leaf extracts of all the plants investigated, have shown a concentration 
dependent $\mathrm{H}_{2} \mathrm{O}_{2}$ scavenging activity. Statistical analysis of the data shows a significant difference $(\mathrm{p}<0.05)$ among the plants in relation to $\mathrm{H}_{2} \mathrm{O}_{2}$ scavenging activity. Lowest $\mathrm{H}_{2} \mathrm{O}_{2}$ scavenging activity was recorded for E. hirta which was 1.6-, 1.9- and 1.1-fold lower than P. tomentosa, D. glaucum and A. indica, respectively (Fig. 3). The $\mathrm{H}_{2} \mathrm{O}_{2}$ scavenging activity of methanolic extracts expressed as $\mathrm{IC}_{50}$ values was in the following order: D. glaucum $>$ P. tomentosa $>$ A. indica $>$ E. hirta (Fig. 3). According to Mobin et al. (2014), $\mathrm{H}_{2} \mathrm{O}_{2}$ scavenging activity of these methanolic extracts could be assigned to the presence of active constituents that that may donate electrons to $\mathrm{H}_{2} \mathrm{O}_{2}$ and thereby neutralizing it to water.

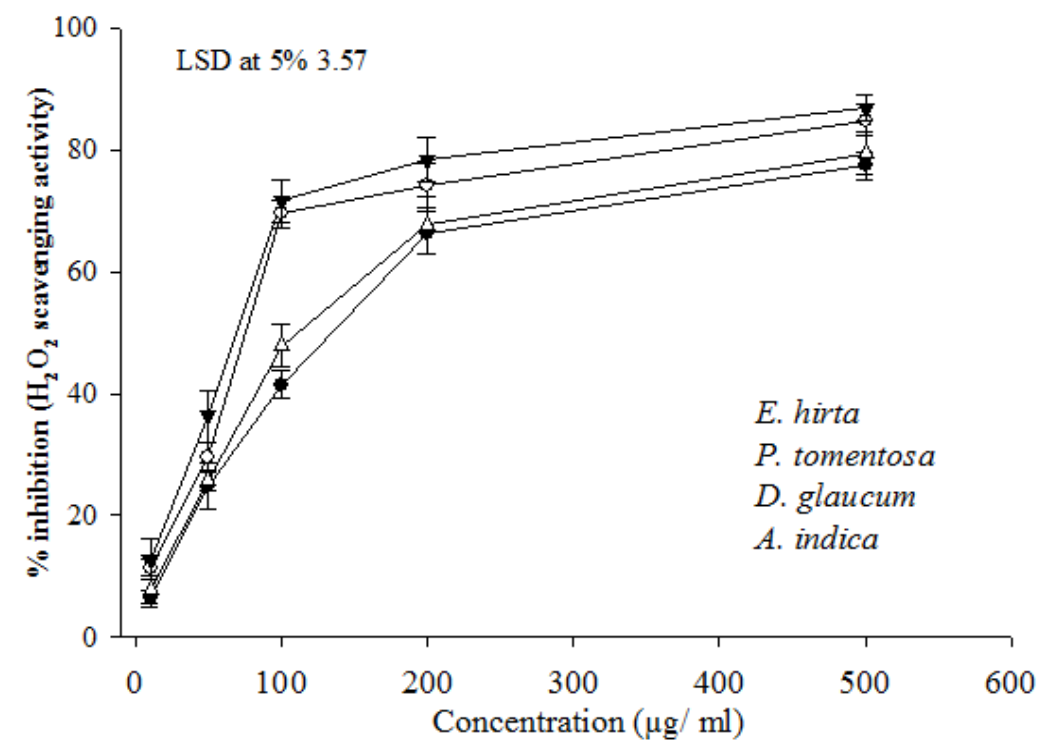

Figure 3. $\mathrm{H}_{2} \mathrm{O}_{2}$ scavenging activities of the methanolic extracts of anti-asthmatic plants Euphorbia hirta, Pergularia tomentosa, Dipterygium glaucum and Acalypha indica. Average of five determinations is presented with LSD at $5 \% \pm S E$

According to Terao (2009), NOX regulates many pathological conditions, especially acute inflammatory condition. Nitrite and peroxynitrite anions are generated when oxygen reacts with the excess NOX that may acts as free radicals (Radi, 2018). In this study, methanolic leaf extracts of all the investigated plants compete with oxygen to react with NOX and thus inhibits the generation of the anions in a dose dependent manner. As in Figure 4 the highest NOX scavenging activity among the analyzed plant extracts were displayed by E. hirta (IC $50=135 \mu \mathrm{g} / \mathrm{ml}$ ). We noted that the NOX scavenging activity of $E$. hirta was $1.2-, 1.4-$ and 1.1-fold more than P. tomentosa, $D$. glaucum and A. indica, respectively (Fig. 4). The bioactive constituents of E. hirta include flavonoids (quercetin and myrcetin), sterols, tannins, and triterpenoids (Attah et al., 2013; Onyeka et al., 2018; Salehi et al., 2019). The abundance of these bioactive substances makes them powerful scavengers.

As in Figure 5, the metal chelating ability of the methanolic leaf extracts of E. hirta, $P$. tomentosa, D. glaucum and A. indica were quantified by the formation of ferrous ionferrozine complex of red colour which absorbs at $562 \mathrm{~nm}$ (Yamaguchi et al., 2000). The ability of a chelating agent to form $\sigma$ bond with a metal, may act as effective scavenger as they lower the redox potential and stabilize the oxidised metal ion (Duh et al., 1999). In the present study the plants show a significant difference response in metal chelating 
activity. Highest and lowest metal chelating activity was noted in P. tomentosa and $D$. glaucum, respectively. Based on $\mathrm{IC}_{50}$ value, the rank order of potency for metal chelating activity of methanolic leaf extracts of all the samples were; $P$. tomentosa $>E$, hirta $>$ A. indica $>$ D. glaucum (Fig. 6). $\mathrm{Fe}^{2+}$, a transition metal can transfer a single electron and can trigger a series of radical reactions even with non-transition metals. $\mathrm{Fe}^{2+}$ - chelating activity depends on flavonoid structures, however, the position of the hydroxyl ion in the molecule determines the proton donating and radical scavenging activity as suggested by Mira et al. (2002), Hou et al. (2003) and de Castilho et al. (2018).

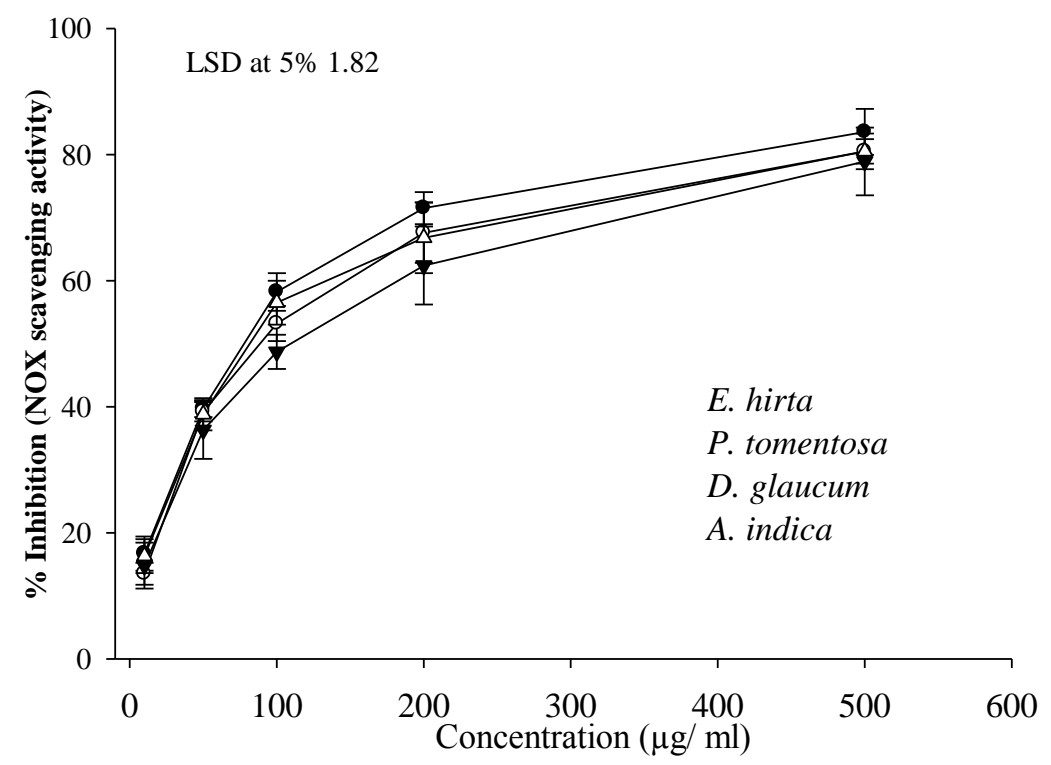

Figure 4. Nitric oxide (NOX) scavenging activities of the methanolic extracts of anti-asthmatic plants Euphorbia hirta, Pergularia tomentosa, Dipterygium glaucum and Acalypha indica.

Average of five determinations is presented with $L S D$ at $5 \% \pm S E$

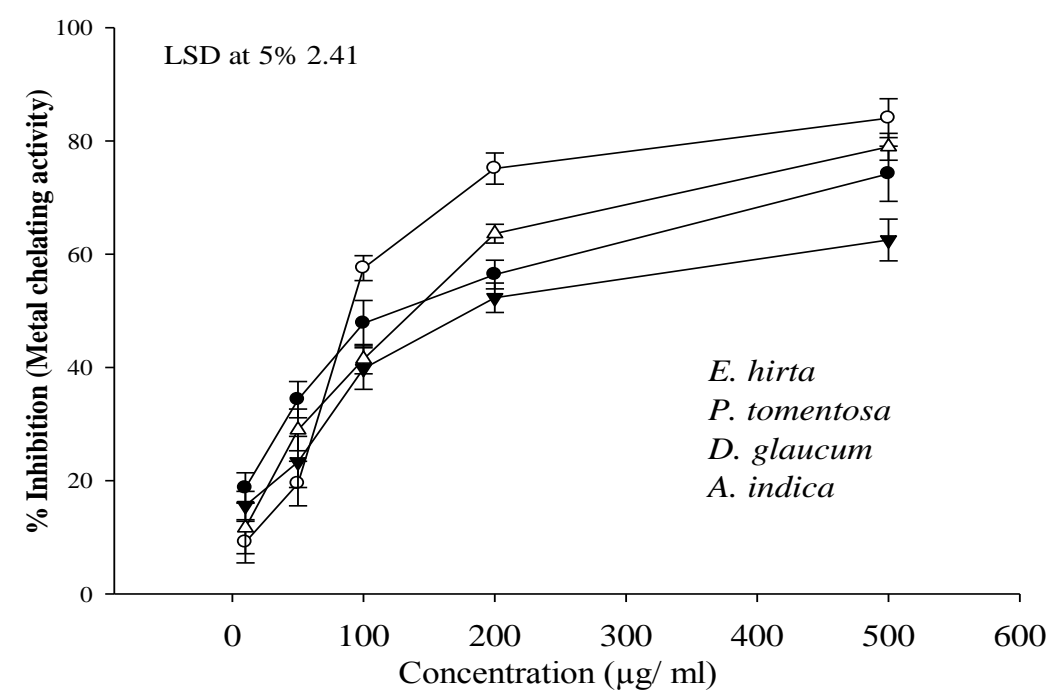

Figure 5. Metal chelating activities of the methanolic extracts of anti-asthmatic plants Euphorbia hirta, Pergularia tomentosa, Dipterygium glaucum and Acalypha indica. Average of five determinations is presented with LSD at $5 \% \pm S E$ 


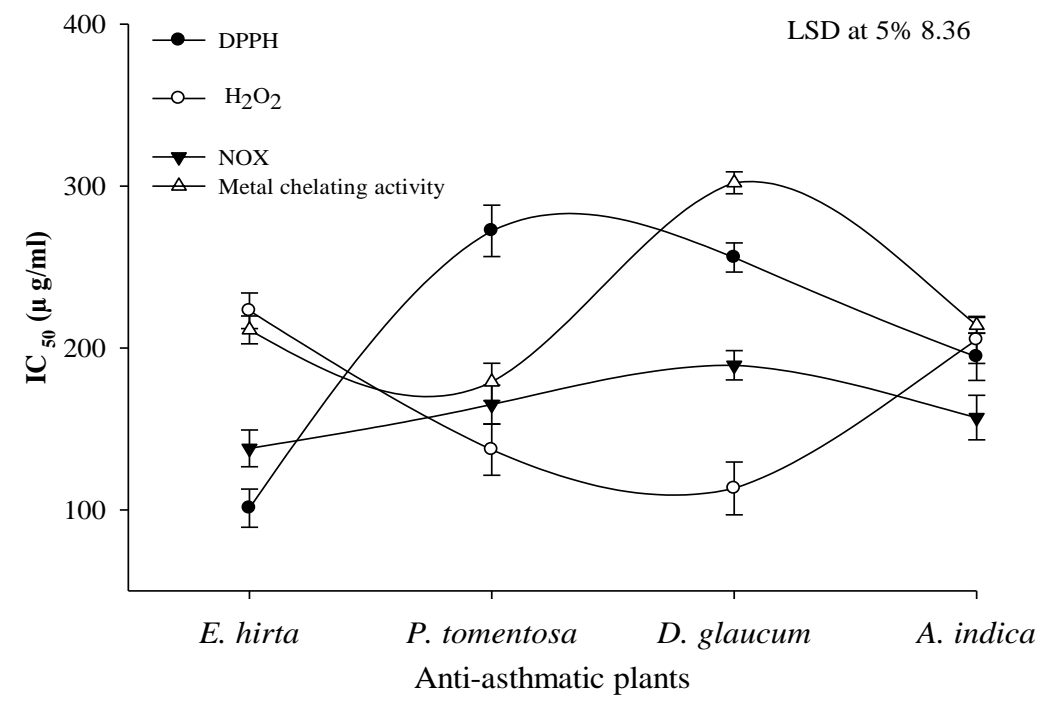

Figure 6. $\mathrm{IC}_{50}$ value $(\mu \mathrm{g} / \mathrm{ml})$ of DPPH radical scavenging, hydrogen peroxide $\left(\mathrm{H}_{2} \mathrm{O}_{2}\right)$ scavenging, nitric oxide (NOX) scavenging and metal chelating activities of the methanolic extracts of anti-asthmatic plants Euphorbia hirta, Pergularia tomentosa, Dipterygium glaucum and Acalypha indica. Average of five determinations is presented with LSD at 5\% $\pm S E$

\section{Conclusions}

The findings of the present study have provided the biochemical evidences for the ethno-pharmacological applications of these anti-asthmatic plants. Based on statistical analysis of the data, it can be postulated that affluence of phenol and flavonoids along with maximum antioxidant capacity, DPPH antiradical activity and NOX scavenging activity in E. hirta makes it worthy of using as an effective anti-asthmatic plant. However, future work should be directed towards the isolation, identification and mode of action of bioactive constituents responsible for strong anti-asthmatic action of these plants.

Acknowledgements. Financial support (Project no. S-0243-1439) by Deanship of Scientific Research (DSR), University of Tabuk is gratefully acknowledged. Authors are also thankful to the Dean, Faculty of Science and head of the Biology Department, University of Tabuk.

\section{REFERENCES}

[1] Alamgeer., Younis, W., Asif, H., Sharif, A., Riaz, H., Bukhari, I. A., Assiri, A. M. (2018): Traditional medicinal plants used for respiratory disorders in Pakistan: a review of the ethno-medicinal and pharmacological evidence. - Chinese Medicine 13: 48. https://doi.org/10.1186/s13020-018-0204-y.

[2] Albayrak, S., Aksoy, A., Sagdic, O., Hamzaoglu, E. (2010): Compositions, antioxidant and antimicrobial activities of Helichrysum (Asteraceae) species collected from Turkey. Food Chemistry 119: 114-122.

[3] Al-Dabbagh, B., Elhaty, I. A., Elhaw, M., Murali, C., Al Mansoori, A., Awad, B., Amin, A. (2019): Antioxidant and anticancer activities of chamomile (Matricaria recutita L.). BMC Research Notes 12: 3. DOI: 10.1186/s13104-018-3960-y. 
[4] Altemimi, A., Lakhssassi, N., Baharlouei, A., Watson, D. G., Lightfoot, D. A. (2017): Phytochemicals: extraction, isolation, and identification of bioactive compounds from plant extracts. - Plants 6: 42. DOI: 10.3390/plants6040042.

[5] Attah, S. K., Ayeh-Kumi, P. F., Sittie, A. A., Oppong, I. V., Nyarko, A. K. (2013): Extracts of Euphorbia hirta Linn. (Euphorbiaceae) and Rauvolfia vomitoria Afzel (Apocynaceae) demonstrate activities against Onchocerca volvulus Microfilariae in vitro. - BMC Complementary and Alternative Medicine 13: 66. DOI: 10.1186/1472-6882-1366.

[6] Bagatini, M. D., Jeandre Jaques. J. A. S., de Oliveira, C. S., de Oliveira, G. A., Pillat, M. M., Mânica, A., Moser, C. S., dos Santos, L. D., Ulrich, H. (2018): Oxidative Stress: Noxious but Also Vital. - In: Atukeren, P. (ed.) Novel Prospects in Oxidative and Nitrosative Stress. InTech Open Publishers, London. DOI: 10.5772/intechopen. 73394.

[7] Batool, R., Khan, M. R., Sajid, M., Ali, S., Zahra, Z. (2019): Estimation of phytochemical constituents and in vitro antioxidant potencies of Brachychiton populneus (Schott \& Endl.) R. Br. - BMC Chemistry13: 10.1186/s13065-019-0549-z.

[8] Bousquet, J., Annesi-Maesano, I., Carat, F., Leger, D., Rugina, M., Pribil, C., El Hasnaoui, A., Chanal, I. (2005): Characteristics of intermittent and persistent allergic rhinitis: DREAMS study group. - Clinical \& Experimental Allergy 35: 728-732.

[9] Cevallos-Casals, B., Byrne, D., Okie, W. R., Cisneros-Zevallos, L. (2005): Selecting new peach and plum genotypes rich in phenolic compounds and enhanced functional properties. - Food Chemistry 96: 273-280.

[10] Das, K., Roychoudhury, A. (2014): Reactive oxygen species (ROS) and response of antioxidants as ROS-scavengers during environmental stress in plants. - Frontiers in Environmental Science https://doi.org/10.3389/fenvs.2014.00053.

[11] de Castilho, T. S., Matias, T. B., Nicolini, K. P., Nicolin, J. (2018): Study of interaction between metal ions and quercetin. - Food Science and Human Wellness 7: 215-219.

[12] Decker, E. A., Welch, B. (1990): Role of ferritin as a lipid oxidation catalyst in muscle food. - Journal of Agricultural and Food Chemistry 38: 674-677.

[13] Duh, P. D., Tu, Y. Y., Yen, G. C. (1999): Antioxidant activity of water extract of harng Jyur (Chrysanthemum morifolium Ramat). - LWT - Food Science and Technology 32: 269-277.

[14] Garcia-Larsen, V., Thawer, N., Charles, D., Cassidy, A., van Zele, T., Thilsing, T., Ahlström, M., Haahtela, T., Keil, T., Matricardi, P. M., Brożek, G., Kowalski, M. L., Makowska, J., Niżankowska-Mogilnicka, E, Rymarczyk, B., Loureiro, C., Bom, A. T., Bachert, C., Forsberg, B., Janson, C., Torén, K., Potts, J. F., Burney, P. G. J. (2018): Dietary intake of flavonoids and ventilatory function in European adults: a GA ${ }^{2}$ LEN study. - Nutrients 10: 95. 10.3390/nu10010095.

[15] Gupta, S. S., Azmi, L., Mohapatra, P. K., Rao, C. V. (2017): Flavonoids from whole plant of Euphorbia hirta and their evaluation against experimentally induced gastroesophageal reflux disease in rats. - Pharmacognosy Magazine 13(Suppl 1): S127-S134. DOI: 10.4103/0973-1296.203987.

[16] Hou, W. C., Lin, R. D., Cheng, K. T., Hung, Y. T., Cho, C. H., Hwang, S. Y., Lee, M. H. (2003): Free radical scavenging activity of Taiwanese native plants. - Phytomedicine 10: $170-175$.

[17] Khan, M. N., Mobin, M., Abbas, Z. K., ALMutairi, K. A. (2016): Impact of varying elevations on growth and activities of antioxidant enzymes of some medicinal plants of Saudi Arabia. - Acta Ecologica Sinica 36: 141-148.

[18] Kumar, S., Malhotra, R., Kumar, D. (2010): Euphorbia hirta: Its chemistry, traditional and medicinal uses, and pharmacological activities. - Pharmacognosy Reviews 4: 58-61. DOI: $10.4103 / 0973-7847.65327$.

[19] Kurutas, E. B. (2016): The importance of antioxidants which play the role in cellular response against oxidative/nitrosative stress: current state. - Nutrition Journal 15: 71. DOI: 10.1186/s12937-016-0186-5. 
[20] Marcocci, L., Maguire, J. J., Droy, M. T. (1994): The nitric oxide scavenging properties of Gingo biloba extract EGb 761. - Biochemical and Biophysical Research Communications 15: 748-755.

[21] Marinova, D., Ribarova, F., Atanasova, M. (2005): Total phenolics and flavonoids in Bulgarian fruits and vegetables. - Journal of Chemical Technology and Metallurgy 40: 255-260.

[22] Mira, L., Fernandez, M. T., Santos, M., Rocha, R., Florencio, M. H., Jennings, K. R. (2002): Interactions of flavonoids with iron and copper ions: a mechanism for their antioxidant activity. - Free Radical Research 36: 1199-1208.

[23] Mobin, M., Khan, M. N., Zahid, K. A. A. (2014): Studies on the in vitro antiradical activity, phenol and flavonoid contents of Saudi medicinal plants of the family Asteraceae having xanthine-inhibitor activities. - World Journal of Pharmacy and Pharmaceutical Sciences 4: 41-52.

[24] Norani, M., Ebadi, M-T., Ayyari, M. (2019): Volatile constituents and antioxidant capacity of seven Tussilago farfara L. populations in Iran. - Scientia Horticulturae 57: 108635. https://doi.org/10.1016/j.scienta.2019.108635.

[25] Onyeka, I. P., Suleiman, M. M., Bako, S. P. (2018): Toxicity effects of methanolic extract of Euphorbia hirta - honey mixture in albino rats. - Journal of Pharmacognosy \& Natural Products 4: 1. DOI: 10.4172/2472-0992.1000147.

[26] Prieto, P., Pineda, M., Aguilar, M. (1999): Spectrophotometric quantification of antioxidant capacity through the formation of a phosphomolybdenum complex: specific application of vitamin E. - Analytical Biochemistry 269: 337-341.

[27] Radi, R. (2018): Oxygen radicals, nitric oxide, and peroxynitrite: Redox pathways in molecular medicine. - Proceedings of the National Academy of Sciences 115: 58395848. https://doi.org/10.1073/pnas.1804932115.

[28] Rayyan, W. A., Alshammari, S. A. G., AL-Sammary, A. M. F., AL-Shammari, M. S. S., Seder, N., Qatoosh, L. F. A., Bostami, M., Mansoor, K., Hamad, M. F., Al-Majali, I. S., Daiyyah, W. A. (2018): The phytochemical analysis and antimicrobial activity of Pergularia tomentosa in north east Kingdom of Saudi Arabia KSA. - Biomedical and Pharmacology Journal 11: 4. http://biomedpharmajournal.org/?p=23959.

[29] Rivera, D. G., Hernández, I., Merino, N., Luque, Y., Álvarez, A., Martín, Y., Amador, A., Nuevas, L., Delgado, R. (2011): Mangifera indica L. extract (Vimang) and mangiferin reduce the airway inflammation and Th2 cytokines in murine model of allergic asthma. Journal of Pharmacy and Pharmacology 63: 1336-1345. 10.1111/j.20427158.2011.01328.x.

[30] Ruch, R. J., Cheng, S. J., Klaunig, J. E. (1989): Prevention of cytotoxicity and inhibition of intercellular communication by antioxidant catechins isolated from Chinese green tea. - Carcinogenesis 10: 1003-1008.

[31] Sai, K., Thapa, R., Devkota, H. P., Joshi, K. R. (2019): Phytochemical screening, free radical scavenging and $\alpha$-amylase inhibitory activities of selected medicinal plants from Western Nepal. - Medicines 6: 70. https://doi.org/10.3390/medicines6020070.

[32] Salehi, B., Iriti, M., Vitalini, S., Antolak, H., Pawlikowska, E., Kręgiel, D., Sharifi-Rad, J., Oyeleye, S. I., Ademiluyi, A. O., Czopek, K., Staniak, M., Custódio, L., Coy-Barrera, E., Segura-Carretero, A., de la Luz Cádiz-Gurrea, M., Capasso, R., Cho, W. C., Seca, A. M. L. (2019): Euphorbia-derived natural products with potential for use in health maintenance. - Biomolecules 9: 337. https://doi.org/10.3390/biom9080337.

[33] Song, F-L., Gan, R-Y., Zhang, Y., Xiao, Q., Kuang, L., Li, H-B. (2010): Total phenolic contents and antioxidant capacities of selected Chinese medicinal plants. - International Journal of Molecular Sciences 11: 2362-2372.

[34] Tanaka, T. (2014): Flavonoids for allergic diseases: present evidence and future perspective. - Current Pharmaceutical Design 20: 879-85. 
[35] Tanaka, T., Iuchi, A., Harada, H., Hashimoto, S. (2019): Potential beneficial effects of wine flavonoids on allergic diseases. - Diseases $7: \quad 8$. https://doi.org/10.3390/diseases7010008.

[36] Terao, J. (2009): Dietary flavonoids as antioxidants. - Forum of Nutrition 61: 87-94.

[37] Thaipong, K., Boonprakob, U., Crosby, K., Cisneros-Zevallosc, L. (2006): Comparison of ABTS, DPPH, FRAP, and ORAC assays for estimating antioxidant activity from guava fruit extracts. - Journal of Food Composition and Analysis 19: 669-675.

[38] Tyśkiewicz, K., Konkol, M., Kowalski, R., Rój, E., Warmiński, K., Krzyżaniak, M., Gil, L., Stolarski, M. J. (2019): Characterization of bioactive compounds in the biomass of black locust, poplar and willow. - Trees. https://doi.org/10.1007/s00468-019-01837-2.

[39] Verma, R., Balaji, B. S., Dixit, A. (2018): Phytochemical analysis and broad spectrum antimicrobial activity of ethanolic extract of Jasminum mesnyi Hance leaves and its solvent partitioned fractions. - Bioinformation 14: 430-439. DOI: $10.6026 / 97320630014430$.

[40] WHO (2018): The Global Asthma Report. - Global Asthma Network, Auckland, New Zealand.

[41] WHO (2019): Global Report on Traditional and Complementary Medicine 2019. - World Health Organization, Geneva.

[42] Williams, R. J., Spencer, J. P. E., Rice-Evans, C. (2004): Flavonoids: antioxidants or signaling molecules? - Free Radical Biology \& Medicine 36: 838-849.

[43] Yamaguchi, F., Ariga, T., Yoshimara, Y., Nakazawa, H. (2000): Antioxidant and antiglycation of carcinol from Garcina indica fruit rind. - Journal of Agricultural and Food Chemistry 48: 180-185.

[44] Yang, L., Wen, K-S., Ruan, X., Zhao, Y-X., Wei, F., Wang, Q. (2018): Response of plant secondary metabolites to environmental factors. - Molecules 23: 762. DOI: 10.3390/molecules23040762.

[45] Youssouf, M. S., Kaiser, P., Tahir, M., Singh, G. D., Singh, S., Sharma, V. K., Satti, N. K., Haque, S. E., Johri, R. K. (2007): Anti-anaphylactic effect of Euphorbia hirta. Fitoterapia 78: 535-9.

[46] Zahidin, N. S., Saidin, S., Zulkifli, R. M., Muhamad, I., Ya'akob, H., Nur, H. (2017): A review of Acalypha indica L. (Euphorbiaceae) as traditional medicinal plant and its therapeutic potential. $\quad-$ Journal of Ethnopharmacology http://dx.doi.org/10.1016/j.jep.2017.06.019. 